\title{
ERRATUM
}

\section{Optimizing nitrogen levels combined with gibberellic acid for enhanced yield, photosynthetic attributes, enzyme activities and artemisinin content of Artemisia annua}

\author{
Tariq AFTAB (凶), M. Masroor A. KHAN, Mohd. IDREES, M. NAEEM, MOINUDDIN \\ Plant Physiology Section, Department of Botany, Aligarh Muslim University, Aligarh- 202 002, India \\ (C) Higher Education Press and Springer-Verlag Berlin Heidelberg 2011
}

Erratum to: Front. Agric. China

DOI: $10.1007 / \mathrm{s} 11703-011-1065-7$

The original version of this article unfortunately contained a mistake. The presentation of Fig. 1 was incorrect, and the corrected figure is given below.

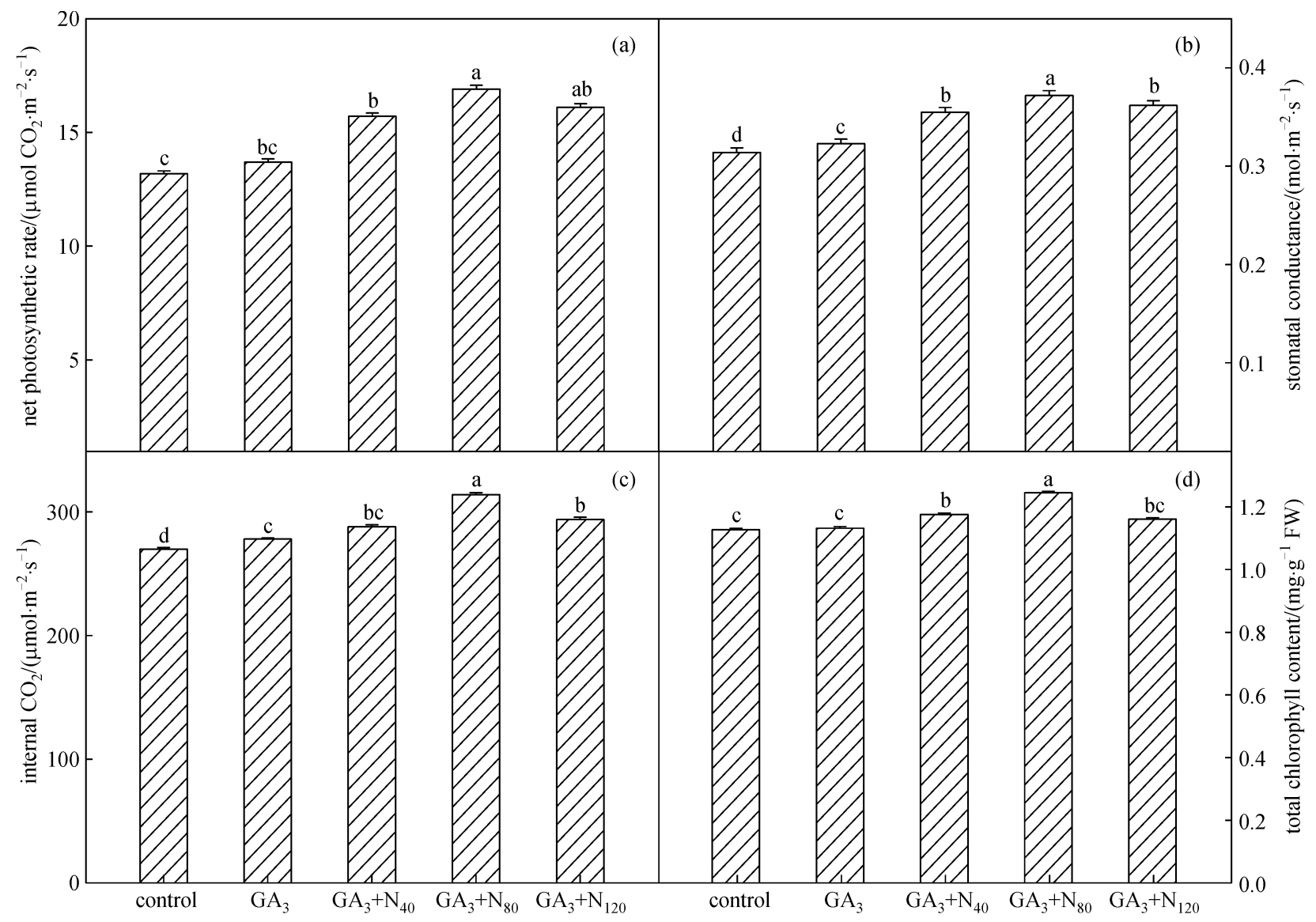

Figure 1 Effect of $\mathrm{GA}_{3}$ and different $\mathrm{N}$ doses on net photosynthetic rate (a), stomatal conductance (b), internal $\mathrm{CO}_{2}(\mathrm{c})$ and total chlorophyll content (d) of Artemisia annua L.

Note: Bars showing different letters are significantly different at $P \leqslant 0.05$ as determined by Duncan's multiple range test. Error bars ( $T$ ) show $S E$. 